\title{
Characterization of Nanoporous Lanthanide-Doped Gadolinium Gallium Garnet Powders Obtained by Propellant Synthesis
}

\author{
R. Krsmanović ${ }^{a}$, S. Polizzi ${ }^{b}$ and P. Canton ${ }^{c}$ \\ Department of Physical Chemistry, University Ca' Foscari of Venice, \\ Via Torino 155/b, I-30172 Venezia-Mestre, Italy \\ aradenka@unive.it, ${ }^{b}$ polizzi@unive.it, ccantonpa@unive.it
}

Keywords: GGG, Garnet, Luminescence, Nanopowders, Propellant Synthesis, Rare Earths.

\begin{abstract}
In the present work we study the nanocrystalline powders of lanthanide-doped $\mathrm{Gd}_{3} \mathrm{Ga}_{5} \mathrm{O}_{12}$ (GGG, gadolinium gallium garnet) prepared using propellant synthesis. A series of GGG samples containing a number of different trivalent lanthanide ions (Tm, Er, Ho, Eu, Sm, Nd, and $\mathrm{Pr}$ ) in different quantities $(1 \%, 5 \%, 10 \%)$ were produced. Samples were characterized by X-ray diffraction (pre- and post calcination) for phase identification and line-broadening analysis, and by electron microscopy (SEM and TEM) for morphological and nanostructural investigation. Thermal behavior of the powder was investigated by thermal gravimetric analysis (TGA) and differential thermal analysis (DTA). The samples have a polycrystalline porous structure. Elemental microanalysis made by energy dispersive X-ray spectroscopy (EDX) detector attached to TEM and XRD unit-cell determinations confirmed that the lanthanides ions entered the structure of GGG. Crystallites have a high degree of disorder.
\end{abstract}

\section{Introduction}

In the last decade the field of luminescence and display materials has gained importance with the study of luminescent particles in the nanometer range. Luminescent nanostructured materials have found application in high-energy photoluminescent (plasma panels) and cathodoluminescent (field emission devices) flat-panel displays as they have required characteristics: thermal and chemical stability, luminous efficiency, nanocrystalline structure, ultrafine particle powder phosphors [1]. Moreover, the new technology demand for size reduction of electronic devices requires the investigation of the physical properties of materials on the nanometer scale. The optical and electronic properties of nanocrystalline materials differ from those of the bulk samples and can be influenced by the particle size [2]. To produce materials with the desired nanostructure many different techniques have been employed like pulsed laser deposition [3], combustion [4], propellant [5] or wet chemical [6] synthesis.

Relatively novel phosphor synthesis technique is a propellant - solution combustion procedure. In this way [1], nanopowders of a number of oxides are produced at low temperature (less than $500^{\circ} \mathrm{C}$ ) and in a rapid way: the reaction takes only few seconds. This simple and environmentally clean technique provides highly crystalline nanopowders in the as-synthesized state, which aggregate to build up a very porous sponge-like microstructure with mass-fractal scaling properties. In previously published works [7, 8], we reported on the structure of lanthanidedoped yttria samples obtained by this method, whereas in the present study we extend the investigation to gadolinium gallium garnet, doped with lanthanides. In particular, garnets represent one of the most important classes of hosts for luminescence applications, especially for trivalent lanthanide ions. They are attractive from a physical standpoint as they are transparent from the UV to the mid-IR. Furthermore, they have high thermal conductivity, hardness, and chemical stability [9]. Also, they are interesting for upconversion phenomena: the generation of visible or UV light from lower energy radiation, usually NIR or IR, through the use of transition metal, lanthanide or actinide ions doping a solid state host $[10,11]$. All rare earth ions have demonstrated upconversion and are particularly suited to undergo this process as they show several excited states with long 
lifetimes that are well matched to the emission wavelengths of several efficient pump laser sources. Much of the interest in upconverting materials is due to their potential applications as IR sensitive phosphors, upconversion lasers and in biological labeling.

\section{Experimental}

\section{Sample Preparation}

$\mathrm{Gd}_{3} \mathrm{Ga}_{5} \mathrm{O}_{12}$ nanocrystals doped with $1 \% \mathrm{Ln}^{3+}(\mathrm{Ln}=\mathrm{Tm}, \mathrm{Er}, \mathrm{Ho}, \mathrm{Eu}, \mathrm{Sm}, \mathrm{Nd}, \mathrm{Pr})$ were prepared using a solution combustion (propellant) synthesis procedure, an important powder processing technique $[5,12]$. This process involves the exothermic reaction between the metal nitrates (oxidizer) and an organic fuel, such as urea, glycine or carbohydrazide. An aqueous solution

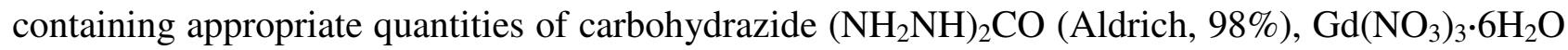
(Aldrich, 99.99\%), $\mathrm{Ga}\left(\mathrm{NO}_{3}\right)_{3} \cdot \mathrm{H}_{2} \mathrm{O}$ (Aldrich, 99.999\%) and $\mathrm{Ln}\left(\mathrm{NO}_{3}\right)_{3} \cdot 6 \mathrm{H}_{2} \mathrm{O}$ (Aldrich, 99.9\%) was prepared. A carbohydrazide-to-metal nitrate molar ratio of 2.5 was employed. The precursor solution was heated with a Bunsen flame and after evaporation of the solvent the auto combustion process took place with the evolution of a brown fume. After a few seconds elapsed, a very porous voluminous mass of the powder (occupied the entire volume of the reaction vessel) was formed. The proposed stoichiometric synthesis reaction is:

$$
(1-x) \mathrm{Gd}\left(\mathrm{NO}_{3}\right)_{3}+5 \mathrm{Ga}\left(\mathrm{NO}_{3}\right)_{3}+3 x \mathrm{Ln}\left(\mathrm{NO}_{3}\right)_{3}+3\left(\mathrm{NH}_{2} \mathrm{NH}\right)_{2} \mathrm{CO} \rightarrow\left(\mathrm{Gd}_{1-x} \mathrm{Ln}_{x}\right)_{3} \mathrm{Ga}_{5} \mathrm{O}_{12}+24 \mathrm{NO}_{2}+6 \mathrm{~N}_{2}+3 \mathrm{CO}_{2}+9 \mathrm{H}_{2} \mathrm{O}
$$

After combustion, the fluffy powders were fired for 1 hour at $500^{\circ} \mathrm{C}$ in order to decompose the residual carbohydrazide and nitrate ions. The generation of a large amount of gaseous products is an important feature of this synthesis as it increases the surface area of the powders and as more gases are liberated, the agglomerates are disintegrated causing more heat to be carried from the system, thereby hindering the particle growth [1]. A series of GGG samples containing 1, 5 and $10 \%$ of a number of different trivalent lanthanide ions (Tm, Er, Ho, Eu, Sm, Nd, and Pr) were produced. Some samples were heated at higher temperatures and for longer time (see below) in attempt to eliminate unwanted minor phases. All samples were lightly ground to a fine powder with a mortar and pestle, and then heat-treated in static air in an alumina crucible followed by natural cooling to room temperature. All samples were kept in air without any further precaution.

\section{Electron microscopy}

The morphology and nanostructure of as-synthesized and heat-treated samples were observed by electron microscopes: scanning electron microscope (SEM) Jeol JSM 5600 LV equipped with an Oxford Instrument 6587 EDX microanalysis detector, and transmission electron microscope (TEM) Jeol 3010 with an ultra high resolution (UHR) pole-piece $(0.17 \mathrm{~nm}$ point resolution), equipped with a Gatan slow-scan CCD camera (Mod. 794) and an Oxford Instrument EDX microanalysis detector (Mod. 6636). Samples for SEM observation were coated with an Au thin film, in order to avoid charging effects, while for TEM observation the powdered samples were dispersed in isopropyl alcohol by sonication (for about five minutes) and a $1 \mu \mathrm{L}$ drop of the solution was deposited onto a copper grid with a holey carbon film.

\section{XRD analysis}

A Philips X'Pert vertical goniometer with Bragg-Brentano geometry, connected to a highly stabilized generator, was used for X-ray diffraction (XRD) measurements. $\mathrm{Cu}-\mathrm{K}_{\alpha}$ Ni-filtered and $\mathrm{Co}-\mathrm{K}_{\alpha}$ Fe-filtered radiation, a graphite monochromator on the diffracted beam and a proportional counter with pulse height discriminator were used. Measurements in a $2 \theta$ range $10-140^{\circ}$ were taken with a step size of $0.05^{\circ}$ and acquisition time of $10 \mathrm{~s}$ per point.

Unit cell-edge values were calculated by using the angular peak position of twenty reflections in the $2 \theta$ range $20-126^{\circ}$. The cell-edge value was extrapolated using a least-square fit in the diagram reporting cell-edge values calculated with the position of each single reflection as a 
function of $\cos \theta \operatorname{cotg} \theta[13,14]$. Peak positions were obtained by previously reported best-fitting procedures [15] where each peak is described by a couple of constrained pseudo-Voigt functions (K $\alpha 1$ and $\mathrm{K} \alpha 2$ profiles) and the background by a polynomial function.

The line-broadening analysis was carried out by the Warren-Averbach method [16] using five pairs of reflections. In accordance with this method, by using the Fourier coefficients of two different peaks belonging to the same family of crystallographic planes, the real distribution of crystallite dimensions and the corresponding distribution of microstrains can be obtained. Both distributions refer to the direction perpendicular to the $(h k l)$ family of crystallographic planes. The values obtained are of the volume-weighted average crystallite size, $\langle D\rangle_{v}$, and the value of $\left\langle\varepsilon^{2}(\mathrm{D})\right\rangle$ at $\langle D\rangle_{\sqrt{ }} / 2$ taken as a measure of the average microstrain. The instrumental broadening was previously deconvoluted by using Stokes' method, adapted to analytically defined profiles.

\section{Thermal analysis}

A Netzsch STA-409/C instrument was used for simultaneous Thermogravimetry (TG) and Differential Thermal Analysis (DTA). Measurements were carried out in air with a scanning rate of $10^{\circ} \mathrm{C} / \mathrm{min}$ and up to $1350^{\circ} \mathrm{C}$. Rhodium crucibles and alumina as inert reference were used.

\section{Results and Discussion}

In previously studied samples $[7,8]$ a mild heat treatment, typically 400 to $500^{\circ} \mathrm{C}$ for one hour was sufficient to eliminate preparation residues. On the contrary, XRD analysis of GGG samples treated

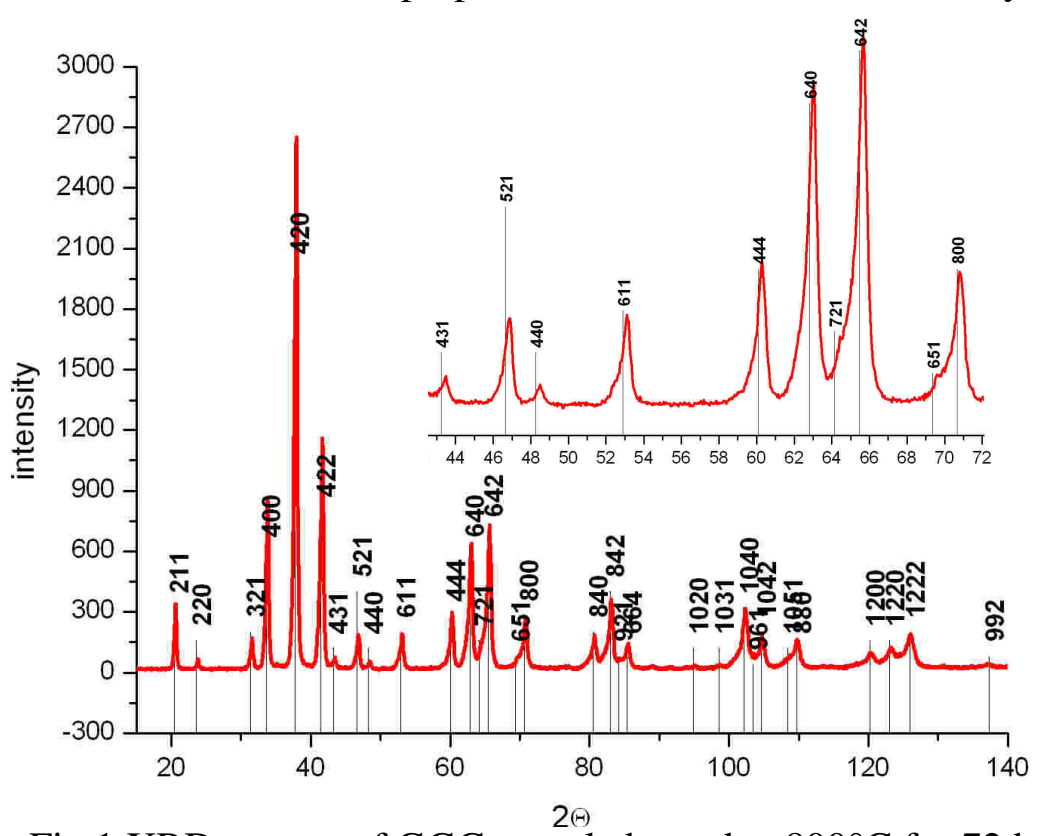

Fig.1 XRD pattern of GGG sample heated at $800^{\circ} \mathrm{C}$ for $72 \mathrm{hr}$ in this way $\left(500^{\circ} \mathrm{C}\right.$ for $\left.1 \mathrm{hr}\right)$ revealed, besides the expected $\mathrm{Gd}_{3} \mathrm{Ga}_{5} \mathrm{O}_{12}$ cubic phase (space group Ia-3d), the presence of minor asymmetric peaks of difficult assignment. For this reason, further heat treatments at higher temperatures (up to $1450^{\circ} \mathrm{C}$ ) were carried out to eliminate these unwanted phases (i.e. GGG:Ho1\% mol was treated at $1450^{\circ} \mathrm{C}$ for 6 hours and the pure GGG cubic phase was obtained but this transformed nanocrystals into big ones).

In order to find out the appropriate temperature for postsynthesis treatment, TG-DTA measurements were carried out.

Since this analysis showed no definite transition temperatures, but only a continuous transformation over the whole scanned temperature range (up to $1350^{\circ} \mathrm{C}$ ), it was argued that the kinetic of the transition was probably rather slow and a longer heat treatment was carried out. Samples were heated at $800^{\circ} \mathrm{C}$ for 72 hours and the resulting XRD pattern (see Fig.1) was that of a pure $\mathrm{Gd}_{3} \mathrm{Ga}_{5} \mathrm{O}_{12}$ cubic phase with only a small increase in crystal size (as judged from the width of the XRD peaks). As each peak of the GGG cubic phase was accompanied by a weak asymmetric peak shifted left to it, we presumed that a (second) isomorphous phase was present. Rietveld refinement was used to describe this asymmetry as due to an isomorphous phase. However, due to high correlation between profile parameters and lattice parameters it was impossible to resolve the two structures. For this reason, a non-structural method was used to calculate the crystallites size and microstrains. Line broadening analysis indicates that the average size of the $\mathrm{Gd}_{3} \mathrm{Ga}_{5} \mathrm{O}_{12}$ crystallites 
is about 20 to $50 \mathrm{~nm}$, with only small differences in the five directions investigated. Peak shifts are observed with different doping. All samples have a high degree of microstrains with most of the values of $\left\langle\varepsilon^{2}(D)>\right.$ at $\left\langle\mathrm{D}>_{\mathrm{v}} / 2\right.$ higher than $1 \times 10^{-3}$. The values of crystallite size $\langle\mathrm{D}\rangle_{\mathrm{v}}$ and microstrains $\left\langle\varepsilon^{2}(\mathrm{D})\right\rangle$ at $\langle\mathrm{D}\rangle_{\mathrm{v}} / 2$ obtained for each pair of crystal planes are listed in Tables 1 and 2 ,

Table 1

\begin{tabular}{|c|c|c|c|c|c|c|}
\hline \multirow{2}{*}{ Dopant } & \multirow{2}{*}{ Mol (\%) } & \multicolumn{5}{|c|}{$\mathbf{D}_{\mathbf{v}}[\mathrm{nm}]$} \\
\hline & & $211 / 422$ & $321 / 642$ & $420 / 840$ & $521 / 1042$ & $611 / 1222$ \\
\hline \multirow{3}{*}{$\mathrm{Tm}$} & \multirow{3}{*}{$\begin{array}{c}1 \\
5 \\
10\end{array}$} & 49 & 47 & 40 & 39 & 43 \\
\hline & & 33 & 38 & 38 & 35 & 47 \\
\hline & & 27 & 48 & 41 & 34 & 39 \\
\hline Er & 1 & 36 & 29 & 24 & $\begin{array}{l}- \\
-\end{array}$ & 24 \\
\hline \multirow{3}{*}{ Но } & \multirow{3}{*}{$\begin{array}{c}1 \\
5 \\
10\end{array}$} & 40 & 33 & 41 & 41 & 38 \\
\hline & & 41 & 43 & 26 & - & 27 \\
\hline & & 32 & 29 & 24 & 39 & 27 \\
\hline (Gd) & - & 26 & 22 & 29 & 29 & 29 \\
\hline $\mathrm{Eu}$ & 1 & 21 & 50 & 49 & - & 37 \\
\hline Sm & 1 & 45 & 42 & 31 & - & 33 \\
\hline $\mathrm{Nd}$ & 1 & 39 & - & 23 & 17 & 45 \\
\hline \multirow{3}{*}{ Pr } & \multirow{3}{*}{$\begin{array}{c}1 \\
5 \\
10\end{array}$} & 15 & 39 & 37 & 34 & 26 \\
\hline & & 27 & 18 & 38 & 38 & - \\
\hline & & 33 & 21 & 18 & 22 & 28 \\
\hline
\end{tabular}

Table 2

\begin{tabular}{|c|c|c|c|c|c|c|}
\hline \multirow{2}{*}{ Dopant } & \multirow{2}{*}{ Mol (\%) } & \multicolumn{5}{|c|}{$<\varepsilon^{2}(D)>\times 10^{-3}$} \\
\hline & & $211 / 422$ & $321 / 642$ & $420 / 840$ & $521 / 1042$ & $611 / 1222$ \\
\hline \multirow{3}{*}{$\mathrm{Tm}$} & \multirow{3}{*}{$\begin{array}{c}1 \\
5 \\
10\end{array}$} & 2.3 & 1.7 & 1.7 & 0.5 & 1.4 \\
\hline & & $<0.1$ & 1.8 & 2.1 & 1 & 1.3 \\
\hline & & 0.8 & 2.6 & 2.0 & 1.2 & 2.0 \\
\hline $\mathrm{Er}$ & 1 & 3.7 & 1.8 & 3.4 & - & 0.9 \\
\hline \multirow{3}{*}{ Ho } & \multirow{3}{*}{$\begin{array}{c}1 \\
5 \\
10 \\
\end{array}$} & 1.4 & $<0.1$ & 1.6 & 1.7 & 1.9 \\
\hline & & 3.6 & 2.5 & 3.0 & - & 2.4 \\
\hline & & 3.7 & 1.5 & 2.9 & 1.7 & 1.6 \\
\hline (Gd) & - & 0.7 & 2.0 & 1.1 & 1.5 & 1.2 \\
\hline $\mathrm{Eu}$ & 1 & 4.2 & 1.6 & 1.9 & - & 1.6 \\
\hline $\mathrm{Sm}$ & 1 & 2.4 & 2.6 & 2.0 & - & 1.7 \\
\hline $\mathrm{Nd}$ & 1 & 3.7 & - & $<0.1$ & - & 2.0 \\
\hline \multirow{3}{*}{$\operatorname{Pr}$} & \multirow{3}{*}{$\begin{array}{c}1 \\
5 \\
10\end{array}$} & 1.1 & 2.1 & 2.9 & 1.5 & 2.3 \\
\hline & & $<0.1$ & $<0.1$ & 2.3 & 1.7 & - \\
\hline & & 5.0 & $<0.1$ & 3.2 & 0.8 & 1.8 \\
\hline
\end{tabular}

respectively.

In order to study the effects of lanthanide ions we made a structural model of the determined cubic structure using the molecular formula $\mathrm{Gd}_{3} \mathrm{Ga}_{2} \mathrm{Ga}_{3} \mathrm{O}_{12}$, space group $\mathrm{O} 10 \mathrm{~h}$ (Ia-3d) and cell dimension $1.24 \mathrm{~nm}$. Considering the ionic radius in unit cell of GGG it is expected that $\mathrm{RE}^{3+}$ ions enter the structure replacing the $\mathrm{Gd}^{3+}$ ions. The values of cell parameter calculated for the studied samples are presented in Table 3. The lattice parameter obtained for pure $\mathrm{Gd}_{3} \mathrm{Ga}_{5} \mathrm{O}_{12}$ sample is 1.2401(7) $\mathrm{nm}$, which is considerably higher than the literature value for samples obtained by conventional synthesis method $(1.2376 \mathrm{~nm})$ [17]. This fact seems to be common for samples obtained by propellant synthesis $[7,8]$ and is not surprising for samples obtained in thermodynamic conditions very far from equilibrium. It was found that the effect of increasing the temperature was that of slightly relaxing the lattice parameter towards literature values: after a "purification" treatment (heat treatment at $800^{\circ} \mathrm{C}$ for $72 \mathrm{hr}$ ) it is $1.2393(2) \mathrm{nm}$. The cell parameter as a function of ionic radius is shown in Fig. 2 for different percentages of lanthanide dopants. It is seen that for the $1 \%$ series the scattering of the data around the value of the un-doped sample (labeled Gd) is much larger than the error bars, suggesting differences in the thermodynamic and kinetic conditions of the combustion reaction due to the presence of the dopant in the starting solution. With the 5\% samples, a trend start to show up, but it is only with the $10 \%$ samples that a linear trend may clearly be seen. Also, for samples containing the same lanthanide, the progressive change with increasing dopant amount seems to be consistent, i.e. the unit cell values decrease with increasing lanthanide amount for the dopants with ionic radius smaller than that of $\mathrm{Gd}^{3+}$ (Ho, Tm), while the opposite happens for the dopant with ionic radius larger than that of $\mathrm{Gd}^{3+}(\mathrm{Pr})$. This demonstrates that the lanthanide ions substitutionally enter the GGG structure even if other factors have a minor influence on the average dimension of the unit-cell and on the degree of order.

Table 3

\begin{tabular}{|c|c|c|c|}
\hline Dopant & Ionic radius $\left[\mathrm{A}^{\circ}\right]$ & Mol (\%) & $\mathbf{a}\left[\mathbf{A}^{\circ}\right]$ \\
\hline $\mathrm{Tm}$ & 0.99 & $\begin{array}{c}1 \\
5 \\
10\end{array}$ & $\begin{array}{l}12.398(1) \\
12.385(2) \\
12.381(2)\end{array}$ \\
\hline $\mathrm{Er}$ & 1.00 & 1 & $12.400(3)$ \\
\hline Ho & 1.02 & $\begin{array}{c}1 \\
5 \\
10\end{array}$ & $\begin{array}{l}12.394(2) \\
12.396(3) \\
12.391(2)\end{array}$ \\
\hline$(\mathrm{Gd})$ & 1.06 & - & $12.393(2)$ \\
\hline $\mathrm{Eu}$ & 1.07 & 1 & $12.400(1)$ \\
\hline $\mathrm{Sm}$ & 1.09 & 1 & $12.405(2)$ \\
\hline $\mathrm{Nd}$ & 1.12 & 1 & $12.402(2)$ \\
\hline $\operatorname{Pr}$ & 1.14 & $\begin{array}{c}1 \\
5 \\
10\end{array}$ & $\begin{array}{l}12.406(2) \\
12.407(3) \\
12.420(3)\end{array}$ \\
\hline
\end{tabular}

The elemental microanalysis of GGG doped with different $\mathrm{RE}^{3+}$ ions was made by EDX. For different particles of the same sample it was observed that the intensity of the dopant peak was rather constant, indicating a homogeneous dispersion within the GGG structure. 
In general, the morphology of pure and doped GGG samples was found to be very similar, i.e. the morphology of the samples is not sensibly altered by the presence of the dopant. In Fig. 3 two typical SEM images are shown at different magnifications. At this sub-micron level the material has a typical porous, sponge-like morphology, as often observed in similar oxides obtained by propellant synthesis $[7,8]$. In contrast to the yttria samples, some apparently more compact areas are present. A careful inspection, however, showed that most of these areas have only a superficial compact laye,r which masks the porous structure underneath. The porous appearance is maintained at the nanometer level (Fig.4) suggesting a fractal organization, as demonstrated by small-angle Xray scattering for previously studied similar samples [8].

So, SEM and TEM observations show that two distinct morphologies are present:

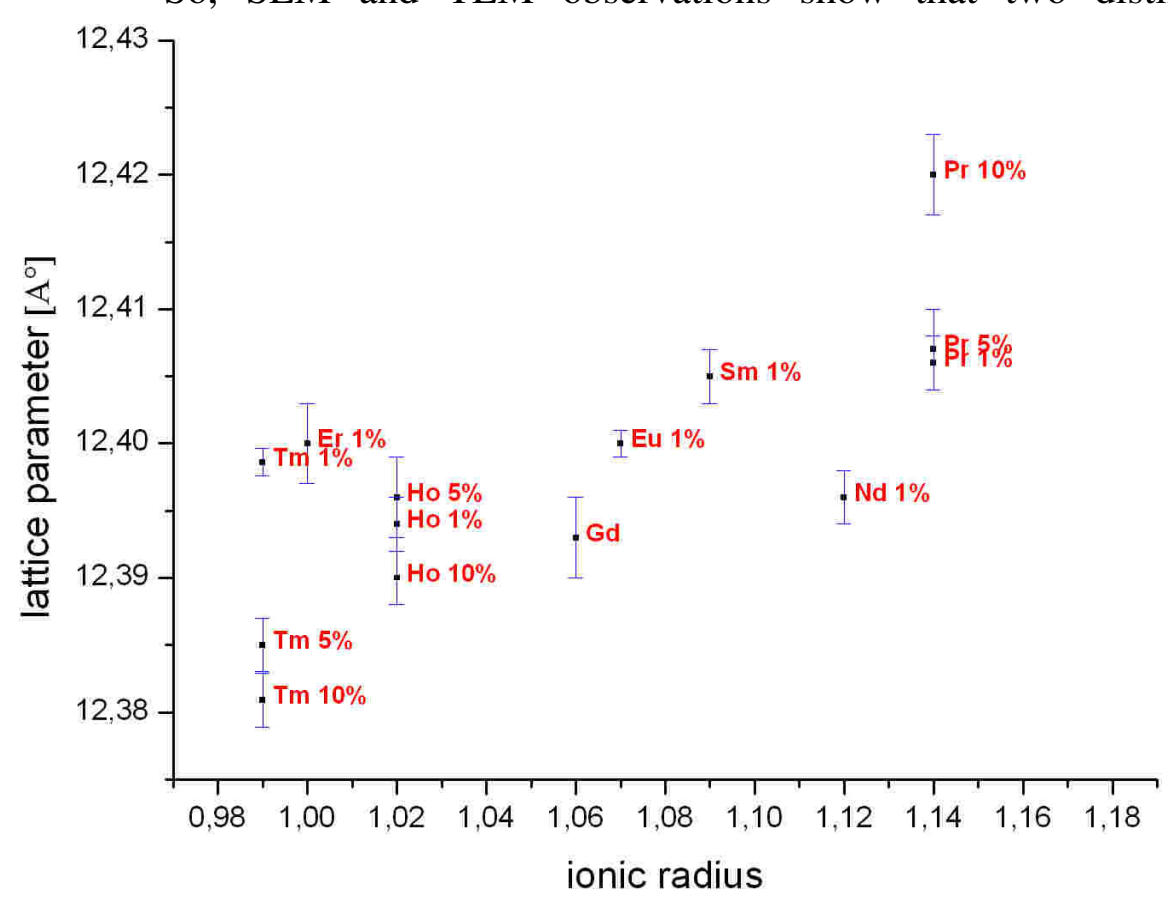

Fig. 2 Lattice parameters shown as function of dopant ionic radius
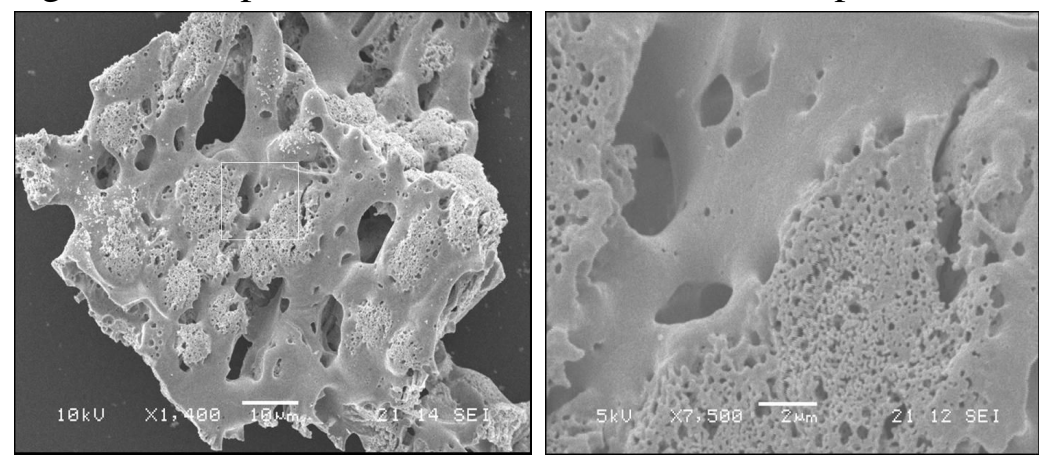

Fig. 3 Typical SEM images of GGG: Eu 1\% mol (heated at $500^{\circ} \mathrm{C}$ for $1 \mathrm{hr}$ ). nanoporous areas immersed in more compact ones. This suggests that two isomorphous phases found by XRD analysis could be respectively porous and compact areas. TEM images (Fig.5) and selected area diffraction (SAD) pattern indicate that the backbone of the material is of a polycrystalline nature and that the crystallites have a broad distribution of sizes in the range of several tens of nanometers. It could be seen that crystalline regions are quite large and often encompasses several pores that explains why XRD broadening analysis gives lower values $[7,8]$. The presence of pores is an indication of the particular process of crystal growth during propellant synthesis.

\section{Conclusions}

It has been shown that propellant synthesis is able to produce, in a direct and economical way, lanthanide-doped nanostructured samples of gadolinium gallium garnet, which may have interesting applications as luminescent materials. Thermal behavior of the powder was investigated by TGA and DTA upon which we found the appropriate temperature for post-synthesis heat treatment. After heating at $800^{\circ} \mathrm{C}$ for $72 \mathrm{hr}$, XRD patterns showed that all samples were made of pure $\mathrm{Gd}_{3} \mathrm{Ga}_{5} \mathrm{O}_{12}$ cubic phase. The expected linear trend of the lattice parameter with dopant amount is clearly seen only for samples with lanthanide content larger than 5\%mol. For smaller doping the effect is 


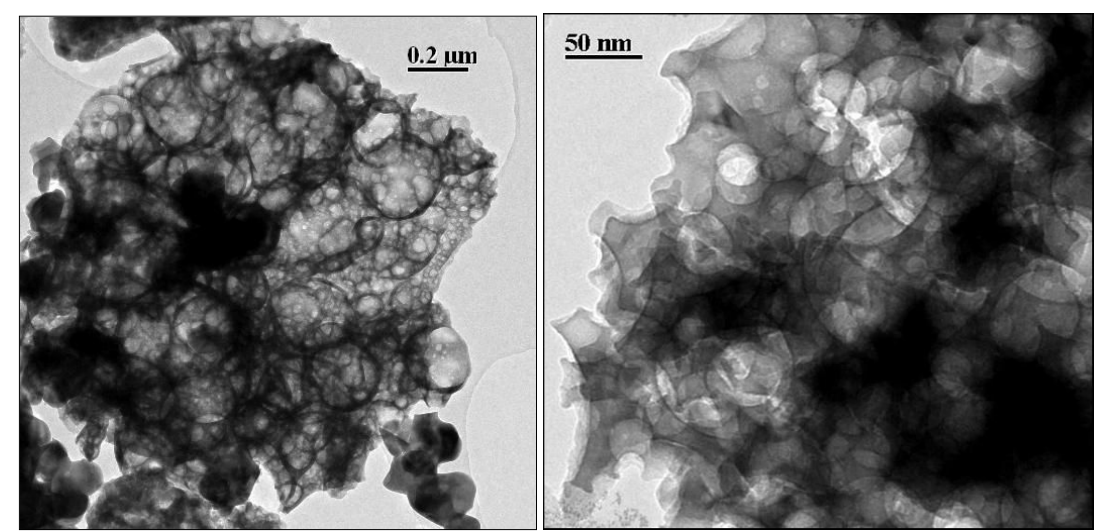

probably masked by the influence of thermodynamics and kinetics conditions of the reaction. Crystallite dimensions, calculated by XRD line broadening, are 20-50 nm, while observations with electron microscopy have shown that crystalline regions have a broader distribution of sizes.

Fig. 4 TEM images of GGG: Er 5\% mol (heated at $800^{\circ} \mathrm{C}$ for $72 \mathrm{hr}$ )

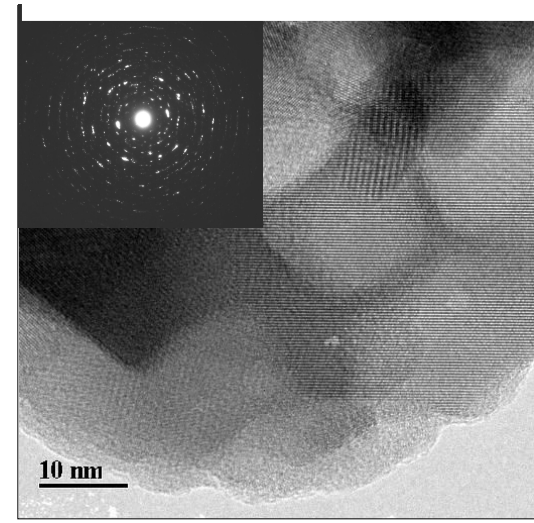

Fig. 5 Typical TEM image of GGG: Er 5\%mol, inset: correspondent selected area electron diffraction pattern confirms polycrystalline structure

\section{Acknowledgements}

We thank Dr. Marco Bettinelli and Dr. Adolfo Speghini of the University of Verona for providing the samples. Dr. Ilaria Nardini and Mr. Tiziano Finotto of the University of Venice are highly acknowledged for their help with thermal and XRD measurements, respectively.

\section{References}

[1] J. McKittrick, L. E. Shea, C.F. Bacalski, E. J. Bosze, Displays 19 (1999), p. 169.

[2] P. Alivisatos, Science 271 (1996), p. 933.

[3] B. M. Tissue, Chem. Mater. 10 (1998), p. 2837.

[4] L. E. Shea, J. McKittrick, O. A. Lopez, E. Sluzky, J. Am Ceram. Soc. 79 (1996), p. 3257.

[5] G. Tessari, M. Bettinelli, A. Speghini, D. Ajò, G. Pozza, L. E. Depero, B. Allieri, L. Sangaletti, Appl. Surf. Sci. 144-145 (1999), p. 686.

[6] P. K. Sharma, M. H. Jilavi, H. Schmidt, V. K. Varadan, Int. J. Inorg. Mater. 2 (2000), p. 407.

[7] G. Fagherazzi, S. Polizzi, M. Bettinelli, A. Speghini, J. Mater. Res. 15 (2000), p. 586.

[8] S.Polizzi, G.Fagherazzi, M.Battagliarin, M.Bettinelli, A.Speghini, J. Mater. Res.16(2001),146.

[9] V. Lupei, Opt. Mater. 19 (2002), p. 95.

[10] W. Lenth, R. M., Macfarlane, Opt. Photon. News 3 (1992), p. 8.

[11] R. Scheps, Prog. Quant. Electron. 2 (1996), p. 271.

[12] Y. Tao, G. Zhao, W. Zhang, S. Xia, Mater. Res. Bull. 32 (1997), p. 501.

[13] N. J. Wagner, (J.B. Cohen ed.) Met. Soc. Conf., 36, Gordon \& Breach, New York (1966).

[14] P. I. Adler, C. N. J. Wagner, J. Appl. Phys. 33 (1962), p. 3451.

[15] S. Enzo, G. Fagherazzi, A. Benedetti, S. Polizzi, J. Appl. Cryst. 21 (1988), p. 536.

[16] B.E. Warren, X-Ray Diffraction, Dover Publications, Reprint edition (1990).

[17] Powder Diffraction File, JCPDS International Centre for Diffraction Data, Swarthmore PA, PDF n. 13-0493. 